Military Technical College

Kobry El-Kobba

Cairo, Egypt

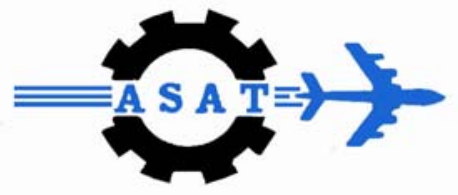

12-th International Conference

on

Aerospace Sciences \&

Aviation Technology

\title{
EFFECTS OF AIR AND FUEL FLOW ON THE DYNAMIC PERFORMANCE FOR A TURBOSHAFT GAS TURBINE ENGINE
}

PART II: ANALYSIS OF THE ENGINE DYNAMIC PERFORMANCE
M. Metwally*,
I. Saleh $* *$ M.G.Rabie ${ }^{\star \star *}$
N. Girgis ****

\begin{abstract}
The effects of air and fuel flow on the engine dynamic performance have been investigated. In part I, the mathematical model, that describes the engine parts and engine control systems, are presented. Herein, the dynamic performance for the studied engine due to the change of the air and fuel flow has been performed. Especially the effect of air flow instabilities on the studied engine performance has been investigated. It has been found that, the mis-synchronization between the air and fuel flow control has a significant effect on turbine inlet temperature. In case of air flow control failure, a sudden thermal failure of the engine parts may occur.
\end{abstract}

\section{KEY WORDS:}

Engine dynamic performance, air and fuel flow control, Electrohydraulic, Proportional, Electromagnetic, Solenoid, Valve, and Actuator.

\section{ABBREVIATIONS}

$\begin{array}{llll}\text { EHSA } & \text { Electrohydraulic servo actuator } & \text { HPT } & \text { High pressure turbine } \\ \text { FMU } & \text { Fuel metering unit } & \text { IGV } & \text { Inlet guide vane } \\ \text { HPCa } & \text { Axial high pressure compressor } & \text { LPC } & \text { Low pressure compressor } \\ \text { HPCr } & \text { Radial high pressure compressor } & \text { LPT } & \text { Low pressure turbine }\end{array}$

\footnotetext{
* Ph. D. Applicant, Egyptian Armored Force.

** Professor, Military Technical Collage

*** Professor, Modern Academy for Engineering and Technology

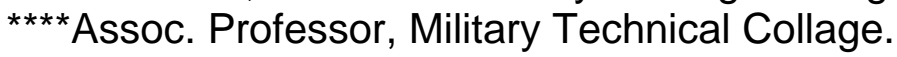




\section{INTRODUCTION}

Gas turbine engines suffer transient operations during load change at design and offdesign conditions. Critical parameters, such as turbine inlet temperature and rotation speed should not exceed certain values for safe and reliable operation. Therefore, a precise prediction of the dynamic behavior of the gas turbine engine is important especially for mis-synchronization between air and fuel flow.

In 1983, Rowen [1] presented a simplified mathematical model of a gas turbine engine. The engine is represented by a first order transfer function. He presented an analysis of frequency response. In 1998, Corsa [2] presented a dynamic response analysis of a gas turbine engine. Simulation program for the engine aero-thermodynamic using Simulink program was carried out. In 2001, Kim, et. al. [3] and [4] presented an investigation of a dynamic performance of a gas turbine engine based on onedimensional conservation equations. They presented also a modified dynamic simulation of full startup procedure for a heavy duty gas turbine engine.

In 2006, Metwally, et. al. [5] employed a contactless controlled spool electrohydraulic proportional actuator to control the air and gases flow through the studied engine. Dynamic simulations of the air and gases flow control through the studied engine have been investigated theoretically and experimentally. The dynamic responses of the engine air and gases flow control system have been analyzed.

The studied gas turbine engine is a turboshaft gas turbine engine. The air flows inlet to the engine and to the power turbine, are controlled by means of two guide vanes cascade. The displacement of the inlet guide vanes is controlled by means of two electrohydraulic servo actuators. The fuel flow rate is controlled by another electrohydraulic controller incorporating a series pressure compensated flow control valve.

The studied turboshaft gas turbine engine is used as a land system power generation. The studied engine has the following specifications: output shaft power 1500hp (1118.5 kW), HPC speed 44500 r.p.m, LPC speed 33800 r.p.m, air flow rate 3.7 kg/s. The available data from the manufacturer is for the design condition only.

In part I of this work [15], the dynamic performance for the studied turboshaft gas turbine engine was investigated. The equations describing the basic system subsystems and controllers were deduced and applied to develop a simulation program. The simulation program of the electrohydraulic servo controllers was validated experimentally. The engine dynamic performance was studied theoretically using the developed computer simulation program. The simulation results of engine air flow control show an agreement with the experimental results.

In this study (part II), the simulation model results of the effect of air and fuel flow control are introduced. The steady state results and dynamic performance of the engine due to change in air and fuel flow are analyzed. Special attention has been taken in this study for the mis-synchronization between the air and fuel flow control. Also the effects of air to fuel ratio on the engine dynamic performance for the absence of engine temperature control are investigated.

The dynamic behavior of the engine to reach the steady state condition at normal operation is not available. The engine dynamic response at instability conditions such as compressor instabilities (surge and stall) and abnormal operation such as (a sudden change in the air or fuel supply or controller malfunction) need to be understood. Thus, 
the mathematical model is performed and simulated to the whole engine subsystems and the air/fuel flow control system [15]. The engine air flow changes affect on the engine dynamic performance is analyzed. The dynamic performance of the engine for unstability conditions and malfunction of the engine control system will be studied.

\section{SIMULATION TECHNIQUE}

The mathematical model of the engine parts and the engine air and fuel flow control has been combined together in one simulation program. SIMULINK program is used to simulate the mathematical model. Sample of the simulation results for the engine with turbine inlet temperature control has been shown in part I of this work [15]. Herein, the main assumption is the engine works at constant supply current to fuel flow control and at the absence of turbine inlet temperature control. This state appeared when the engine is suffered from a deep surge; a frequency associated to the surge (unstable zone) may not be recognized by the engine sensors.

\section{RESULTS AND DISCUSSIONS}

Figures (1) to (4) show the steady state performance of the studied gas turbine engine. While figures (5) to (9) show the dynamic behavior of the studied gas turbine engine.

\subsection{Steady state simulation results}

Figure (1) shows the effect of IGV command current on the engine intake air flow rate. The air flow rate is directly proportional to the IGV position, at constant compressor speed and constant air density. The IGV command current is the main parameter that controls the position of the IGV. In the previous work [5], it was shown that $(0.3 \mathrm{~A})$ is the mid-position current for the EHSA controlling the IGV. The maximum air flow rate is at zero current supplied to the IGV-EHSA where the actuator is fully extended. The position of the IGV doesn't depend on the EHSA supply pressure; it depends only on the supplied current. The IGV-EHSA supply pressure affects on the response of the IGV to reach the required position. 


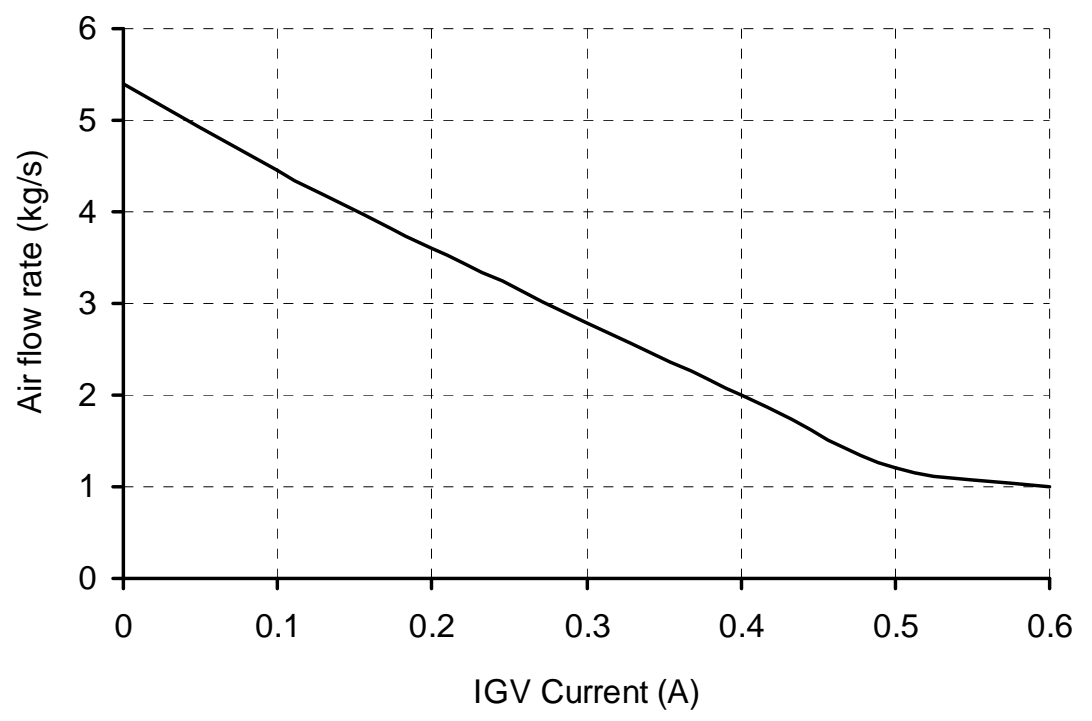

Fig. (1) The engine intake air flow for different IGV command current.

Figure (2) shows the effect of the IGV command current on the air to fuel ratio at constant fuel flow to the combustor. At IGV command currents below the null current $(0.3 \mathrm{~A})$, it results an increase in the intake air mass flow rate and in the air to fuel ratio. The maximum air to fuel ratio is at IGV current (OA), where the IGV is fully open. The minimum air to fuel ratio is at $(0.7 \mathrm{~A})$ where the IGV is at close position.

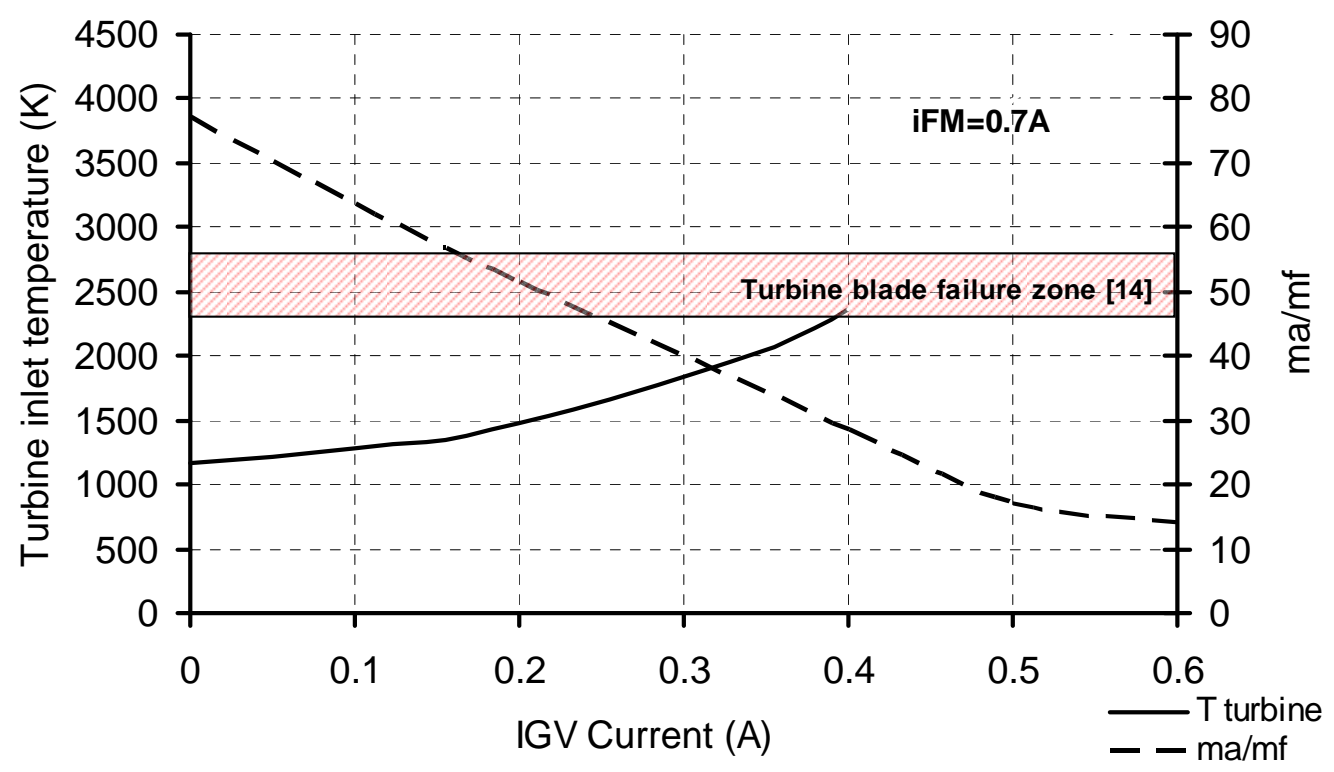

Fig. (2) Air to fuel ratio and turbines inlet temperature for different IGV command current.

The air to fuel ratio could be affected by the engine instabilities, in compressor (surge and stall) or control system malfunction. The air and fuel mixture has two processes in the combustion chamber in gas turbine engine, cooling and combustion processes. In 
piston engine the air to fuel ratio ranges 11-15:1. The air to fuel ratio in the gas turbine engine is in range of 40-70:1 to accomplish the cooling and combustion processes. Figure (2) shows that at low air to fuel ratio (rich mixture) the air is enough to complete the combustion process, but on account of cooling process. At air to fuel ratio below 40:1, the turbine inlet temperature couldn't increase to the value more than the dissociation of the gasses depend on the fuel type. This will increase the turbine inlet temperature to the blade failure zone, where the turbine blades are usually made from a titanium material.

The results showed that, to avoid high thermal load on the turbine blade it is important to have synchronization between the IGV command current and the FMU command current. At extreme cases of low air to fuel ratio (rich mixture) the turbine inlet temperature can increase to the limit of turbine blades failure.

Figure (3) shows the steady state effect of air to fuel ratio on the engine compressors pressure ratio when the engine works without a turbine temperature limit control. The pressure of the gas turbine engine compressors is affected by main parameters; air flow rate, compressor speed and compressor geometry. At constant compressor geometry and speed, the behavior of the compressor pressure may be varied by the effect of engine instabilities at low air flow rate and constant fuel flow to the combustor.

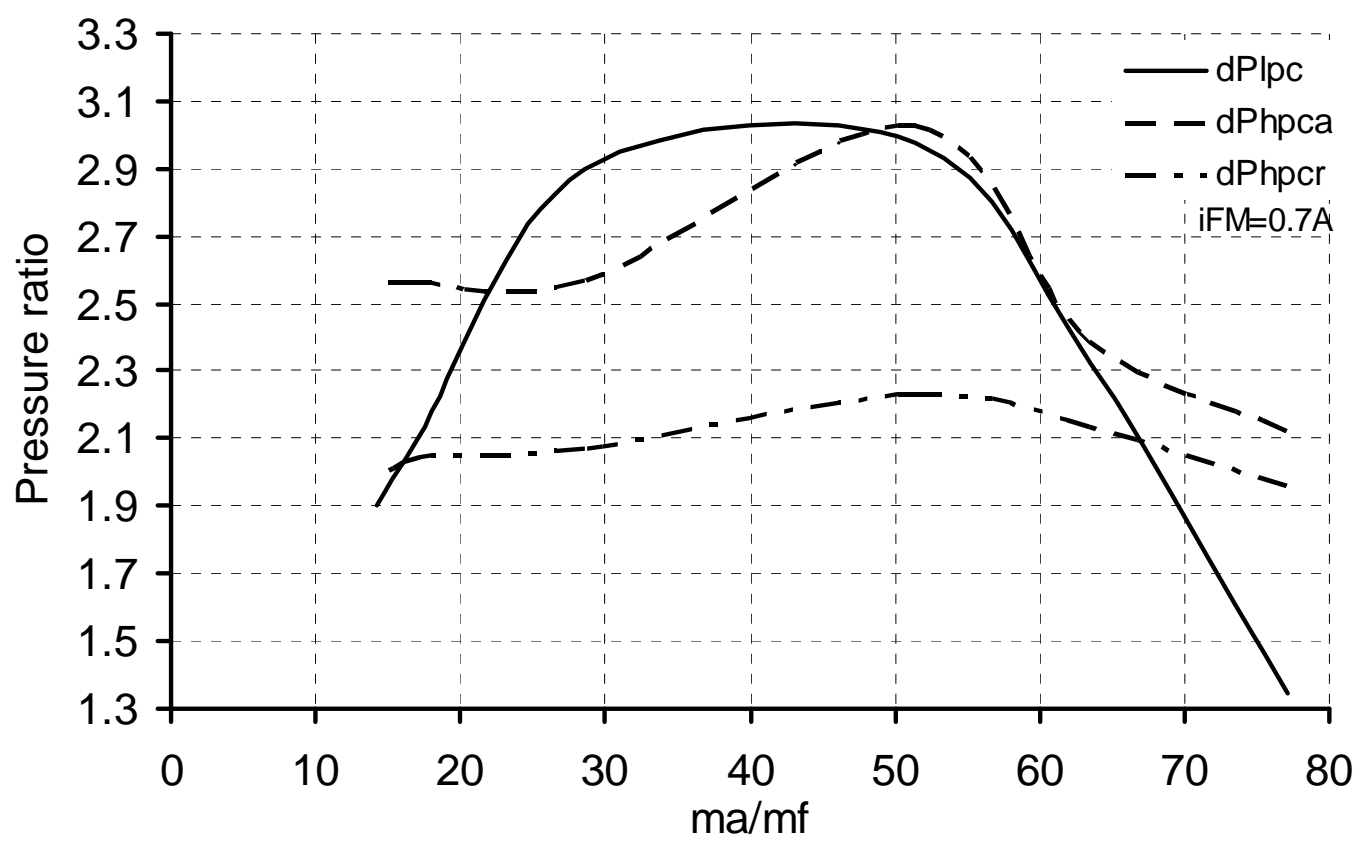

Fig. (3) Compressors pressure ratio for different air to fuel ratio.

Figure (4) shows the simulation results of the effect of air to fuel ratio on the on the engine output shaft power at a mismatching between the air and fuel flow control. At low air to fuel ratio an increase in the shaft output power due to the increase the heat energy from the fuel burning which may reach the flame temperature. 


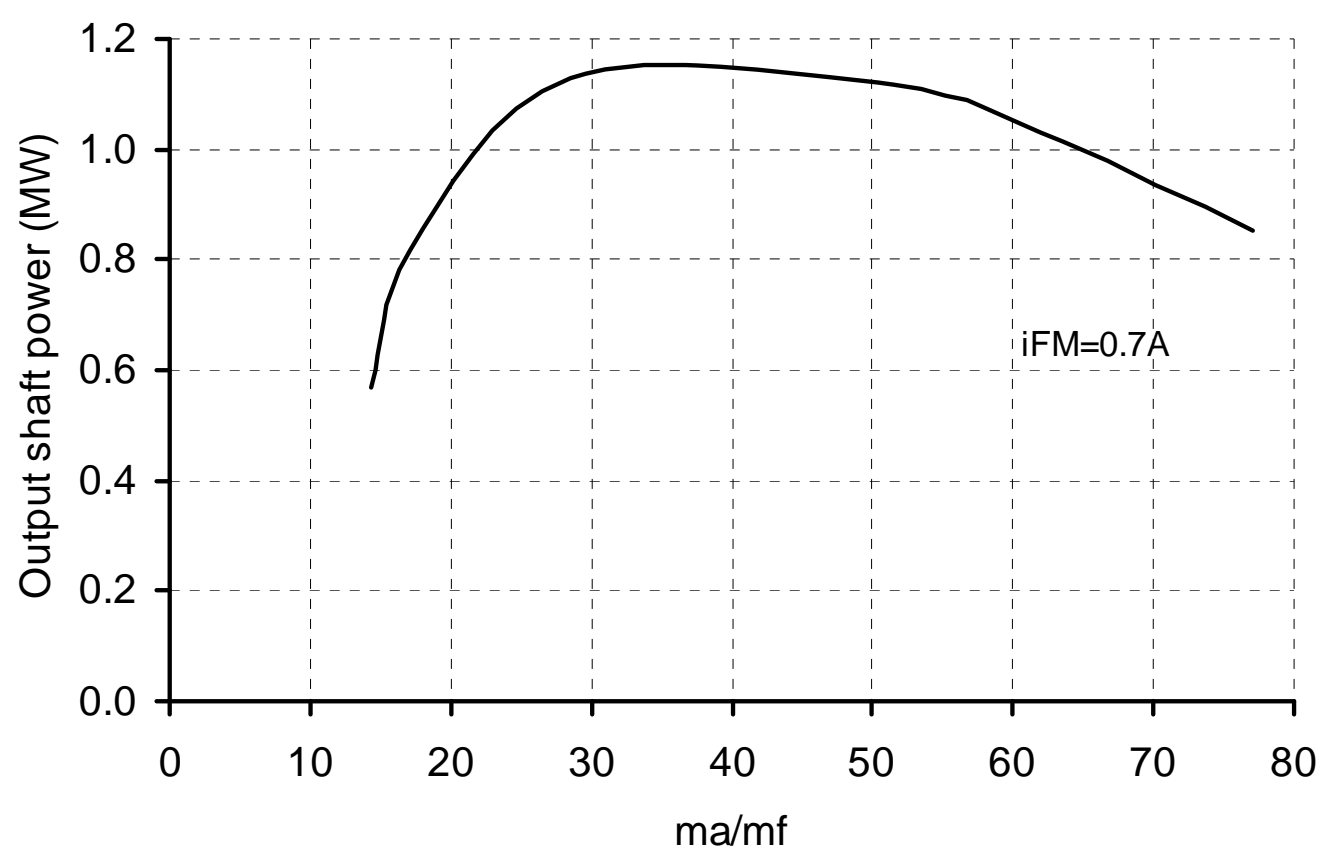

Fig. (4) Engine output shaft power for different air to fuel ratio.

\subsection{Dynamic performance simulation results}

The simulation of the engine dynamic performance is performed by step input of the IGV and FMU command currents. These represent the action of the operator when it is needed to change the engine speed or when the engine encounters an instability condition.

Figure (5) shows the transient response of the turbine inlet temperature due to step change in the IGV supply current and at constant FMU supply current. This case represents the mismatching in the air and fuel flow control systems. This mismatching could be appeared when the engine enters an instability working zone. The high frequencies associated to the compressor instabilities may not be recognized by the sensing units of the engine controls. This can lead the engine to work at a low air to fuel ratio as at (0.5A and $0.6 \mathrm{~A}$ IGV supply current). The turbine inlet temperature in this case could reach the flame temperature about $\left(2500^{\circ} \mathrm{K}\right)$. This high temperature could decrease the turbine blade service life and at extreme cases the thermal failure can be occurred. Figure (5) shows that the turbine inlet temperature takes about 1.5 second to reach it steady state values. 


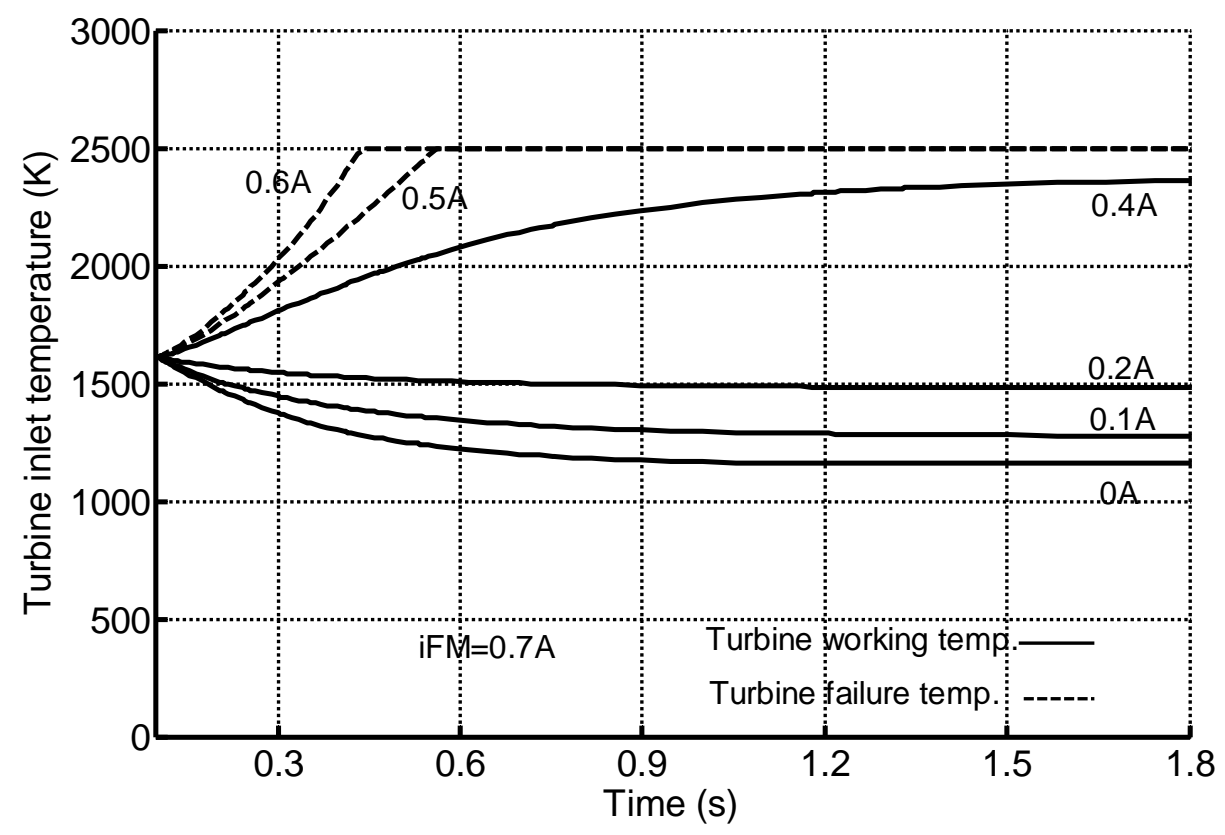

Fig. (5) Transient response of the turbine inlet temperature for constant FMU and different IGV command currents for the engine.

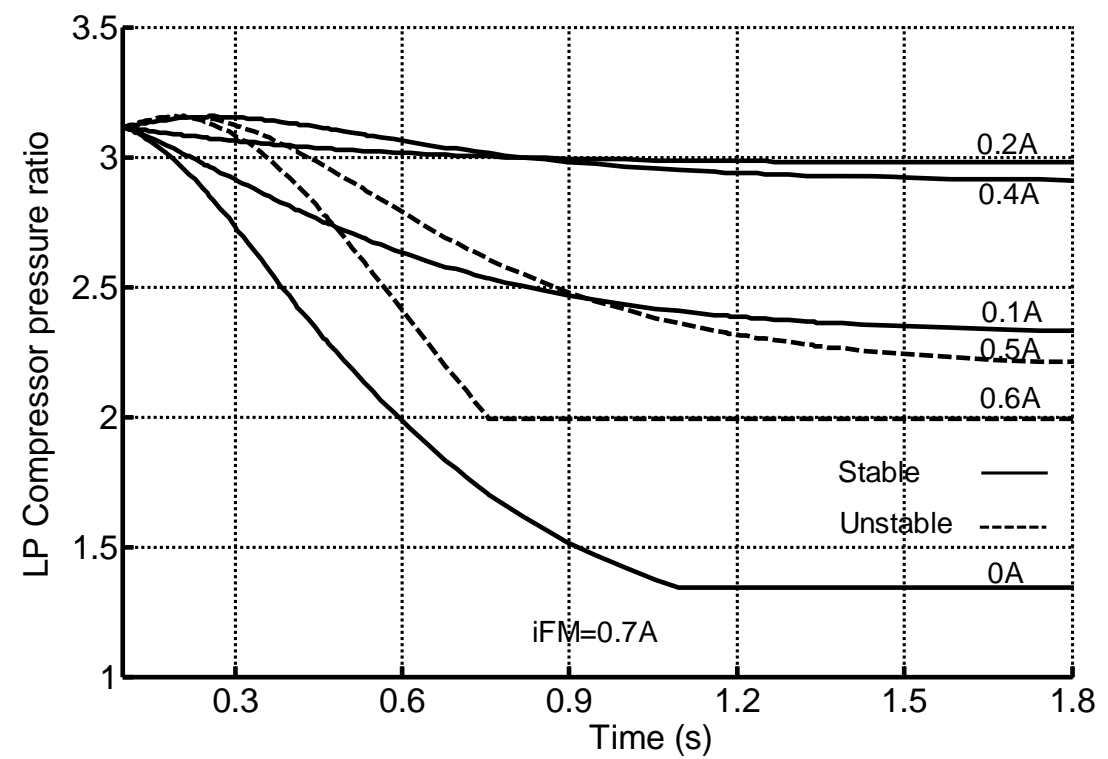

Fig. (6) Transient response of the LPC pressure ratio for constant FMU and different IGV command currents for the engine.

The transient response of the pressure ratio in the engine compressor due to the change in the IGV and constant FMU command currents are shown in Fig. (6), Fig.(7) and Fig. (8). The mismatching between the air and the fuel flow control not only effects on the engine overheating but it effects on the compressor to work on the instability working zone. The compressor pressure takes about 1.5 second to reach the steady state values. The IGV currents $(0.5$ and $0.6 \mathrm{~A})$ show that the engine will be unstable where the compressor speed is constant. 


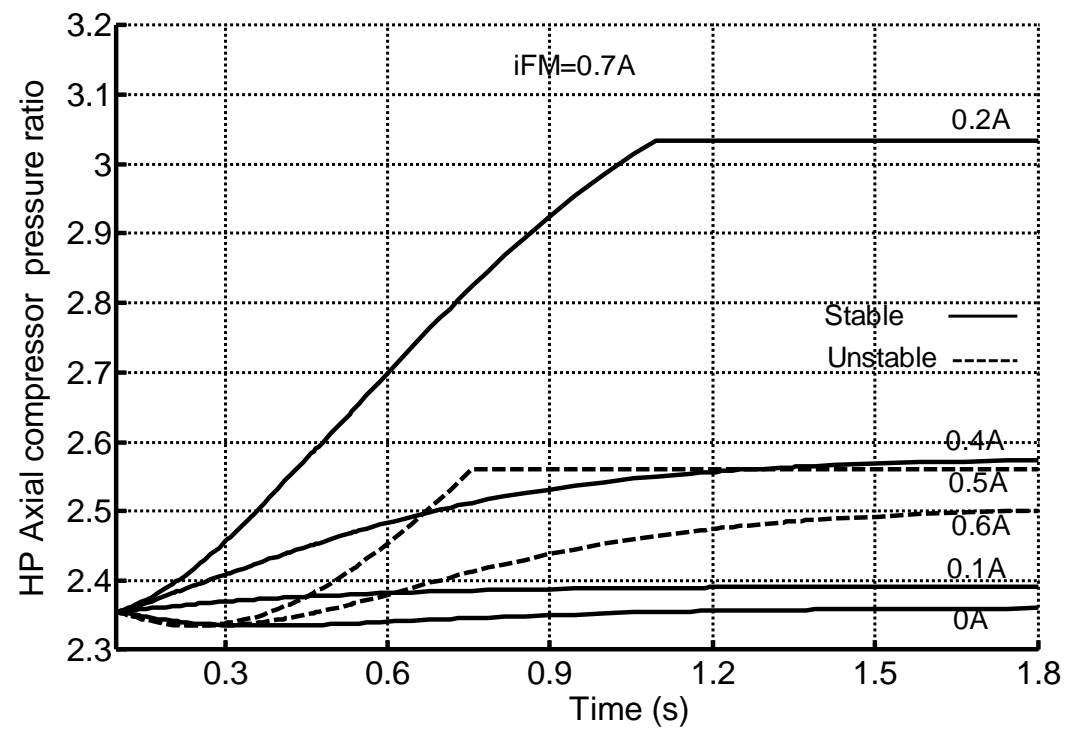

Fig. (7) Transient response of the HPCa pressure ratio for constant FMU and different IGV command currents for the engine.

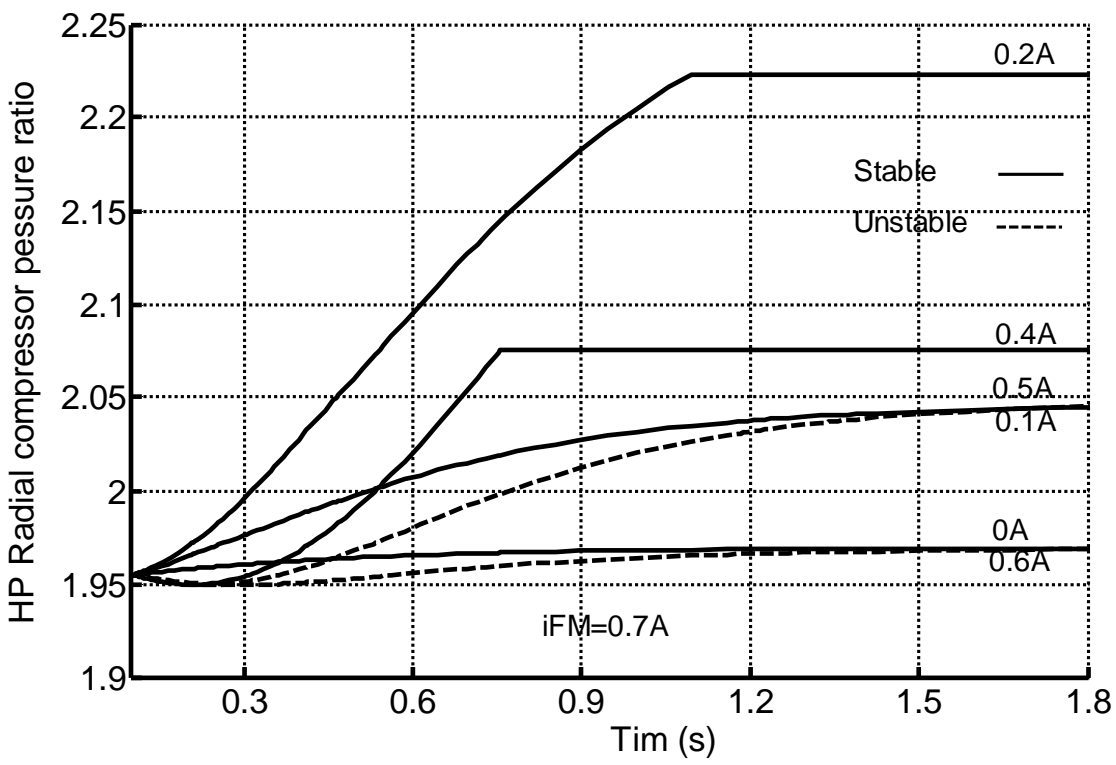

Fig. (8) Transient response of the HPCr pressure ratio for constant FMU and different IGV command currents for the engine.

Figure (9) shows the effect of the step change in the IGV current on the engine output power at constant FMU command current. The mismatching between the air and fuel flow control could lead the engine to loss its output power. A drop in the engine output power appears at IGV current $0.5 \mathrm{~A}$ and $0.6 \mathrm{~A}$ due to engine instabilities and the decrease in the air flow to the engine. The engine output power takes about 1.5 second to reach its steady state values. 


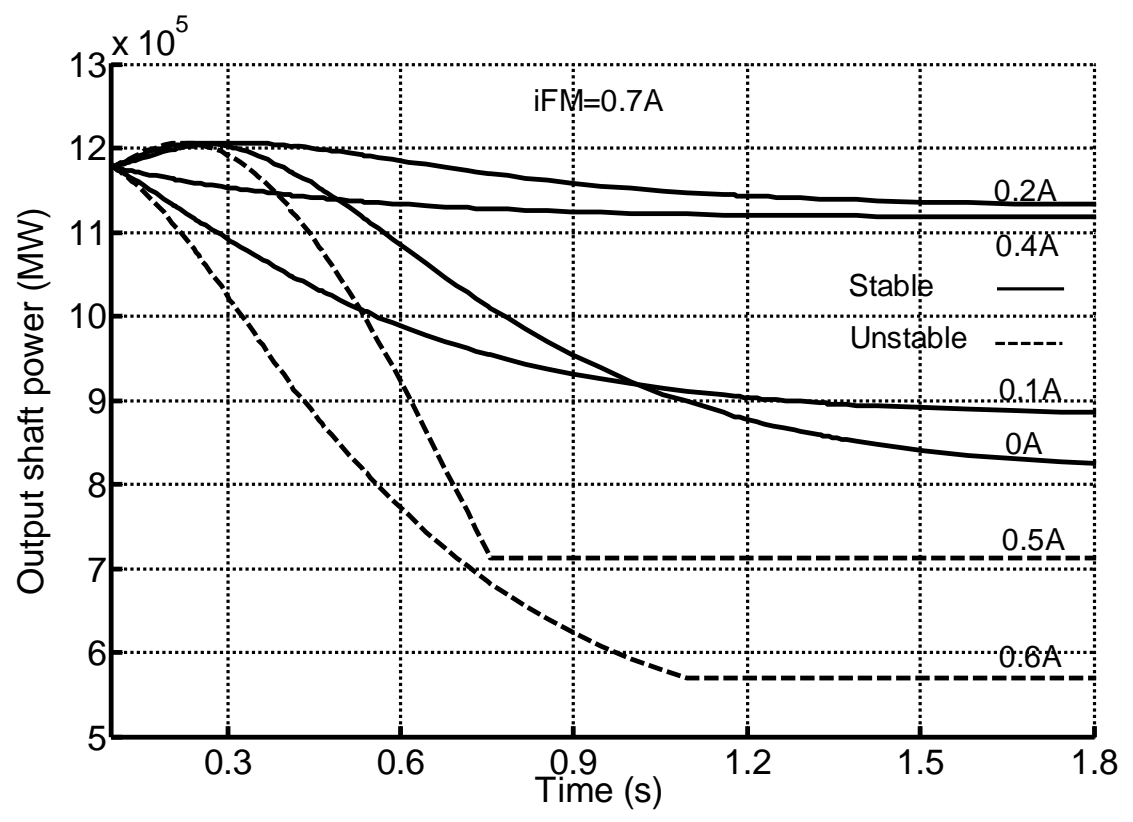

Fig. (9) Dynamic response of the output shaft power for constant FMU and different IGV command currents for the engine.

\section{CONCLUSIONS}

The available data from the engine manufacturer is for the design point only. The mathematical model of the engine parts and the engine control system is performed to study the effect of air and fuel flow rate on the engine dynamic performance. Simulink program is used to simulate the mathematical models. The steady state performance represents the effect of change of intake air flow rate on the different engine performance parameters. It is found that the air flow rate has a significant effect on the different engine performance parameters. The dynamic simulation shows that the engine control system mal-operation can leads to engine overheating.

Synchronization between the IGV and the FMU command currents has a special importance to avoid thermal failure in the turbine blades. The results show that the settling time for considered engine performance found to be about 1.5 second.

\section{REFERENCES}

[1] Rowen W. I., 1983, "Simplified Mathematical Representations of Heavy-Duty Gas Turbine Engine", Transaction of ASME, Journal of Engineering for Gas Turbine and Power, Vol.105, pp. 865-869.

[2] Crosa G., et. al., 1998, "Heavy-Duty Gas Turbine Plant Aero-thermodynamics Simulation Using Simulink", Transaction of ASME, Journal of Engineering for Gas Turbine and Power, Vol. 120, pp.550-556.

[3] Kim J. H., et. al., 2001, "Model Development and Simulation of Transient Behavior of Heavy Duty Gas Turbines", Transaction of ASME, Journal of Engineering for Gas Turbine and Power, Vol. 123, pp. 589-594. 
[4] Kim J. H., et. al., 2002, "Dynamic Simulation of Full Startup Procedure of Heavy-Duty Gas Turbines", Transaction of ASME, Journal of Engineering for Gas Turbine and Power, Vol. 124, pp. 510-516.

[5] Metwally M., et. al., 2006, "Dynamic Performance of an Electrohydraulic Servo Actuator with Contactless Controlled Spool", 12th International Conference on Applied Mechanics and Mechanical Engineering, MTC, Cairo, Egypt.

[6] Cohen, et. al., 1984, "Gas Turbine Theory", Longman Group Limited, London.

[7] Arno Schmitt et. al., 1989, "Proportional and Servo Valve Technology", Mannesmann Rexroth Gmbh, USA.

[8] Norvelle F.D., 2000, "Electrohydraulic Control System", Prentice Hall inc., New jersey, USA.

[9] Chueng N.C. et. al., 1996, "Modeling of a Non Linear Solenoid Towards the Development of a Proportional Actuator", IEEE Industrial Electronic Society annual general, Vol. 2, pp. 21-30.

[10] Schoenau G., et. al., 1999, "Parameter Estimation in a Solenoid Proportional Valve Using OLS and MLH Techniques", Mechanical Engineering Department of University of Saskatchewan, Canada.

[11] Lua A.C. et. al. 2001, "Proportional Assist Ventilation System Based on Proportional Solenoid Valve Control", Journal of Medical Engineering and Physics, Vol. (23), pp. 381-389.

[12] Rabie M.G., 2005, "Fluid Power Engineering", Published by the author, Cairo, Egypt.

[13] Rabie M.G., 2005, "Automatic Control for Mechanical Engineering Students ", Published by the author, Cairo, Egypt.

[14] Avallone E. A., 1996, "Marks' Standard Hand Book for Mechanical Engineers", Tenth edition, McGraw Hill, USA.

[15] Metwally M. et. al., 2007, "Effect of Air and Fuel Flow on the Dynamic Performance for a Turboshaft Gas Turbine Engine, Part I: Modeling and Simulation", under publication. 